\title{
Impact of nutritional recovery with linear growth on the concentrations of adipokines in undernourished children living in Brazilian slums
}

\author{
Vinicius J. B. Martins ${ }^{1 *}$, Andrea P. O. Neves ${ }^{1}$, Maria do C. P. Franco ${ }^{1}$, Ana P. G. Clemente ${ }^{2}$ and \\ Ana L. Sawaya ${ }^{1}$ \\ ${ }^{1}$ Department of Physiology, Federal University of São Paulo, Rua Botucatu 862, 2nd andar, Edifício de Ciências Biomédicas, \\ São Paulo, CEP 04023-060, Brazil \\ ${ }^{2}$ Federal University of Alagoas, Faculdade de Nutrição, Campus A. C. Simões, Avenida Lourival Melo Mota, s/n, Cidade \\ Universitária, Maceió - AL, CEP 57072-900, Brazil \\ (Submitted 20 November 2013 - Final revision received 31 March 2014 - Accepted 3 June 2014 - First published online 28 July 2014)
}

\section{Abstract}

Undernutrition in early life has been reported to be closely associated with the development of non-communicable diseases in adulthood. Adequate treatment is important for reversing these effects. In the present study, we investigated the effects of undernutrition and anthropometric recovery on the weights and heights of children in relation to the concentrations of leptin, adiponectin and plasminogen activator inhibitor-1 (PAI-1). A total of 119 children (aged 6-16 years) from the slums of São Paulo were selected according to their nutritional status and divided into three groups as follows: control (healthy without intervention, $n$ 38) with a height-for-age $Z$ score (HAZ) and a BMIfor-age $Z$ score (BAZ) $>-1 \cdot 6$; undernourished (HAZ and/or BAZ $<-1 \cdot 6, n 54$ ); recovered from undernutrition (after treatment in a rehabilitation centre; HAZ and BAZ $>-1 \cdot 6, n$ 27). Blood samples were collected to determine insulin, glucose, leptin, adiponectin and PAI-1 concentrations. Leptin concentrations in the undernourished group were lower than those in the control and recovered groups (mean 0.92 (95\% CI $0.67,1.25), 2.03$ (95\% CI $1.46,2 \cdot 82)$ and 1.66 (95\% CI 1.15, 2.44) ng/ml, $P=0.003$ ), which had similar leptin concentrations. There were no differences in adiponectin and PAI-1 concentrations among the groups. A positive correlation between waist circumference and leptin concentrations was observed in all the girls and boys of the control group (control: $r 0 \cdot 729, P<0 \cdot 01$; undernourished: $r 0.490, P<0.05$; and recovered: $r 0.829, P<0.01 ; r 0.673, P<0.05)$. Stronger correlations between leptin and insulin concentrations were observed in the recovered group. The results of the present study indicate that normal leptin concentrations are found when normal height and weight are achieved.

\section{Key words: Adipokines: Undernutrition: Nutritional recovery}

In addition to functioning as an energy store, adipose tissue is the local synthesis site for many hormones such as leptin, adiponectin and plasminogen activator inhibitor-1 (PAI-1), which are collectively referred to as adipokines ${ }^{(1)}$. Alterations in the concentrations of these adipokines are associated with the development of CVD, obesity and hyperinsulinaemia ${ }^{(1-3)}$.

Studies in children with kwashiorkor or marasmus have shown leptin concentrations of these children to be significantly lower than those of healthy children ${ }^{(4)}$. Similar findings have also been reported in children with mild and moderate undernutrition $^{(5)}$. However, PAI-1 concentration data are much scarcer in undernourished children. According to the literature, there are no reports of serum adiponectin values in these children. In one study, similar concentrations of PAI-1 have been found in stunted children and non-stunted controls $^{(6)}$. In another study, accelerated weight gain in children with a low birth weight or with a history of underweight in childhood has been found to be positively associated with high concentrations of PAI-1 in adulthood and an increased risk of $\mathrm{CVD}^{(7)}$.

Undernutrition is one of the most important public health problems in the world; it is responsible for the highest mortality rate in children and has long-lasting effects ${ }^{(8,9)}$. In recent years, evidence on the double burden of malnutrition has grown, because a high prevalence of undernutrition coexists with an increasing risk of obesity, diabetes and CVD in middle- and low-income countries ${ }^{(10-13)}$. Undernutrition in early life and/or stunting trigger physiological changes in adulthood, such as a higher susceptibility to fat accumulation $^{(14,15)}$, particularly central fat ${ }^{(16)}$, lower fat oxidation ${ }^{(17)}$,

Abbreviations: BAZ, BMI-for-age $Z$ score; CREN, Centre for Nutritional Recovery and Education; HAZ, height-for-age $Z$ score; HOMA-S, homeostasis model assessment of insulin sensitivity; PAI-1, plasminogen activator inhibitor-1; WC, waist circumference; WHR, waist:hip ratio.

*Corresponding author: V. J. B. Martins, fax +55 1150832108 , email vifisio@yahoo.com.br 
lower energy expenditure ${ }^{(18,19)}$, obesity ${ }^{(20)}$, hypertension ${ }^{(21)}$, type 2 diabetes $^{(22)}$ and CVD. In addition, some studies ${ }^{(23-25)}$ have shown that an accelerated growth in weight during nutritional recovery, primarily in childhood, increases the risk of non-communicable diseases in the future. In this context, an adequate recovery from undernutrition is required to prevent the onset of such diseases in the future.

National policies to fight undernutrition have generally consisted of money transfer programmes or food distribution and/or supplementation to high-risk groups. However, careful supervision and follow-up are needed to ensure food intake of adequate quality and quantity, in addition to the adequate treatment of co-morbidities, such as infections and anaemia. Given this purpose, the Federal University of São Paulo established the Centre for Nutritional Recovery and Education (CREN) to develop nutritional rehabilitation approaches for direct intervention in the complex socio-economic and familial situations of urban slums ${ }^{(26,27)}$. These interventions last an average of 2-3 years and aim for the complete recovery of a child's height and weight. Previous data from this research group have shown that children with this pattern of nutritional recovery achieve normal plasma glucose and insulin concentrations ${ }^{(28)}$ and body composition, in addition to normal bone mineral density ${ }^{(29)}$.

Postnatal nutrition is known to affect the major components of the metabolic syndrome ${ }^{(30)}$. Despite this evidence, studies reporting an appropriate profile of nutritional treatment, including both height and weight recoveries, for undernourished children are almost non-existent. In the present study, the concentrations of leptin, adiponectin and PAI-1 were compared in three groups of children: undernourished children; children who had nutritionally recovered after treatment at the CREN; well-nourished control children. The hypothesis was that normal serum concentrations of adipokines are found after long-term nutritional recovery when normal weight, and especially height, is achieved.

\section{Methods}

\section{Sample population and study design}

A cross-sectional study was conducted on a convenience sample ( $n$ 119) of thirty-eight control children of both sexes aged between 6 and 16 years, fifty-four undernourished children and twenty-seven children who had recovered from undernutrition. The anthropometric criteria for inclusion in the groups were as follows: a height-for-age $Z$ score (HAZ) and a BMI-for-age $Z$ score (BAZ, weight in $\mathrm{kg} /$ height $^{2}$ in metres for age) $>-1.6\left(5\right.$ th percentile $\left.{ }^{(31)}\right)$ to be included in the control group; a BAZ and/or a HAZ $<-1.6$ to be included in the undernourished group; a HAZ and a BAZ $>-1.6$ to be included in the recovered group.

The undernourished and control groups were selected on the basis of anthropometric assessments conducted in schools and youth centres in low-income areas of the city of São Paulo. On this occasion, measurements were carried out in the entire population of children at the schools/centres ( $n 3369$ children), and all the undernourished and healthy control children were invited to participate in the study. The children who chose to participate in the study and whose condition fulfilled the inclusion criteria were included in the study. The children who had recovered from undernutrition were selected from the CREN database. Home visits were made after the identification of these children in the database, and during these visits the children and their families were invited to return to the CREN and participate in the study. All children treated between 1999 and 2010 who agreed to participate and whose condition was in accordance with the inclusion criteria were included in the present study. The average treatment time at the CREN was 38.46 ( $\operatorname{se} 3.70)$ months (minimum $=6$ months and maximum $=85$ months). The average weight-for-age $Z$ score and HAZ at admission were -1.96 (SE $0 \cdot 18$ ) and -2.04 (SE 0.22), respectively, and the mean increments during treatment were 0.90 (sE $0 \cdot 18$ ) and 1.00 (sE $0 \cdot 14$ ) (weight-for-age $Z$ score and HAZ, respectively). The present study was carried out after a median discharge time of 63.5 (SE 6.21) months.

Screening was carried out in all the children to ensure the absence of parasites, infections and anaemia, and if any of these were found, the children were treated before inclusion in the study. Children who had CVD or renal, neurological or endocrine diseases were excluded from the study. The identified undernourished children were referred for treatment at the CREN following data collection.

All the families signed the Free and Informed Consent Form, and the study was approved by the Research Ethics Committee of the Federal University of São Paulo in accordance with the Declaration of Helsinki (UNIFESP - CEP 1302/09).

\section{Description of the treatment at the Centre for Nutritional Recovery and Education}

The CREN offers outpatient assistance to children with mild undernutrition and day hospital care for those with moderate/severe undernutrition from 0 to 71 months of age. Dietary interventions are based on Brazilian staple diets of natural foods (rice, beans, meat, fruits and vegetables, etc.) and do not contain formula (except for a short period of time or for specific intolerances), with continuous monitoring for and intervention in cases of infections, parasites and anaemia (for more details, see das Neves et al. ${ }^{(29)}$ and Alves-Vieira Mde et $\left.a l^{(26)}\right)$. Paediatricians, nutritionists, social workers and psychologists participate in the treatment programme. The paediatrician monitors the clinical status, laboratory findings and anthropometric progress of each child. The nutritionist follows the child's diet and corrects dietary errors identified during treatment. Laboratory tests (blood and stools) are carried out each semester. The children are also given $\mathrm{Fe}$ and vitamin (A, B, C and D) supplements in prophylactic doses.

\section{Anthropometry}

The children were weighed in their underwear and asked to position themselves so that their weight was equally distributed on both sides of a digital scale platform with a capacity of

(n 3369 children), and all the undernourished and healthy 
$150 \mathrm{~kg}$ and a precision within $100 \mathrm{~g}$ (model SD-150; Country Technologies). Their heights were determined using a stadiometer (AlturExata; TBW) with a precision within $0.1 \mathrm{~cm}$. The nutritional status indicators HAZ and BAZ were employed using the WHO curves as standards. The AnthroPlus program (version 1.0.4; WHO) was used to assess nutritional status.

Waist circumference (WC) and hip circumference were measured using a tape measure with an accuracy of $1 \mathrm{~mm}$ when the children were standing with their abdomens relaxed and their arms relaxed beside their bodies. The WC was measured by placing the tape at the midpoint between the last rib and the iliac crest, and the hip circumference was measured over the greater trochanter. The waist:hip ratio (WHR) was obtained by dividing the WC by the hip circumference.

\section{Pubertal staging}

Pubertal stages were assessed by a physician at the CREN using Tanner's criteria ${ }^{(32)}$. The children were then classified according to the cut-off values established by the $\mathrm{WHO}^{(33)}$. Girls with breast stages equal to or greater than 2 (M2) and boys with genital stages equal to or greater than 3 (G3) were considered pubertal; children whose breast or genital stages were below these levels were considered prepubertal.

\section{Biochemical analyses}

Blood samples were collected by a nurse at CREN's research facility in the morning after a $10 \mathrm{~h}$ fast. The samples were centrifuged, and the plasma was stored at $-22^{\circ} \mathrm{C}$. The concentration of insulin was determined by chemiluminescence with a Unicel DXI 800 (Beckman Coulter). The concentration of glucose was determined by colorimetric enzymatic method with ADVIA reading equipment at a wavelength of $340 \mathrm{~nm}$ (Siemens). The Homeostasis Model Assessment (HOMA) calculator $\mathbb{C}$ (The University of Oxford ${ }^{(34)}$ ) for Microsoft Excel spreadsheets was used to determine HOMA-S (insulin sensitivity) from fasting plasma glucose and specific insulin concentrations.

\section{Multiplex immunoassay}

The serum concentrations of total adiponectin, leptin and total PAI-1 were determined using ELISA with a commercially available Multiplex kit (Milliplex Luminex xMAP; Millipore). The serum concentrations of adiponectin and total PAI-1 were determined using the Milliplex MAP Human Adipokine Kit (code HADK1MAG-61K), and the concentration of leptin was determined using the Milliplex MAP Human Metabolic Hormone Kit (code HMHMAG-34K) ${ }^{(35)}$. The intra-assay accuracy of the method was assessed on the basis of control samples, which were included in each assay. The samples and standards were processed using the Luminex 200 (Luminex Corporation) instrument platform and the related MagPix Analyser with xPONENT/Analyst software (Luminex Corporation).

\section{Statistical analyses}

Anthropometric variables were analysed by a two-way ANOVA using sex and group as factors. Comparisons between pubertal groups were made using the $\chi^{2}$ test. Biochemical variables were log-transformed (Naperian) and analysed using a two-way ANCOVA with sex and group as factors and with age and pubertal stage as covariates, followed by Tukey's post hoc test. The geometric means (back-transformed means of the log-transformed data) were calculated, and these are given in the tables. Data are expressed as means with their standard errors or means and 95\% CI. Correlations between anthropometric and biochemical variables were evaluated using Pearson's correlations. The analyses were carried out using SPSS for Windows (version 20.0; IBM Corporation), with $\alpha=0.05$.

A power calculation was performed a priori using Gpower 3.1.9 (University of Kiel, Germany), which showed that a sample size of 119 subjects would provide a power of more than $65 \%$.

\section{Results}

The anthropometric characteristics of the study groups are summarised in Table 1 . The age of children in the undernourished

Table 1. Anthropometric characteristics of the study groups (Mean values with their standard errors)

\begin{tabular}{|c|c|c|c|c|c|c|c|c|}
\hline & \multicolumn{2}{|c|}{$\begin{array}{c}\text { Control } \\
(n \text { 25G, 13B) }\end{array}$} & \multicolumn{2}{|c|}{$\begin{array}{l}\text { Undernourished } \\
(n 19 \mathrm{G}, 35 \mathrm{~B})\end{array}$} & \multicolumn{2}{|c|}{$\begin{array}{c}\text { Recovered } \\
\text { (n 14G, 13B) }\end{array}$} & \multicolumn{2}{|c|}{$P \dagger$} \\
\hline & Mean & SE & Mean & SE & Mean & SE & Effect of group & Effect of sex \\
\hline Age (years) & $10 \cdot 00$ & 0.40 & $11.67^{*}$ & 0.33 & $10 \cdot 18$ & 0.45 & 0.003 & 0.602 \\
\hline HAZ & -0.09 & 0.15 & $-1 \cdot 35^{\star}$ & 0.12 & -0.49 & $0 \cdot 17$ & $<0.001$ & $\ddagger$ \\
\hline BAZ & -0.01 & 0.14 & $-1.69^{*}$ & $0 \cdot 12$ & -0.44 & 0.16 & $<0.001$ & $\ddagger$ \\
\hline WC $(\mathrm{cm})$ & 57.91 & 0.95 & $55 \cdot 30$ & 0.79 & $56 \cdot 82$ & 1.07 & 0.108 & 0.808 \\
\hline Waist:hip ratio & 0.82 & 0.01 & 0.83 & 0.01 & 0.82 & 0.01 & 0.748 & $<0.001$ \\
\hline
\end{tabular}

G, girls; B, boys; HAZ, height-for-age $Z$ score; BAZ, BMI-for-age $Z$ score; WC, waist circumference.

* Mean value was significantly different from those of the control and recovered groups.

†ANOVA two-way (group and sex): age \{group $(F(2,113)=6.22)$, $\operatorname{sex}(F(1,113)=0.27)$, interaction factor $(F(2,113)=1.31) ; P=0.272\}$; $H A Z$ \{group $(F(2,113)=21.74)$, sex $(F(1,113)=0.91)$, interaction factor $(F(2,113)=1 \cdot 15) ; P=0.321$; ; BAZ \{group $(F(2,113)=43.73)$, sex $(F(1,113)=0.05$, interaction factor $(F(2,113)=3.17) ; P=0.046$; WC \{roup $(F(2,113)=2 \cdot 27)$, sex $(F(1,113)=0.06)$, interaction factor $(F(2,113)=1.17) ; P=0.312\}$; waist:hip ratio group $(F(2,112)=0.291)$, sex $(F(1,112)=13.96)$, interaction factor $(F(2,112)=0.87) ; P=0.419\}$. $\ddagger \mathrm{HAZ}$ and $\mathrm{BAZ}$ values for age and sex have been calculated previously. 
Table 2. Metabolic characteristics of the study groups $†$

(Mean values and $95 \%$ confidence intervals)

\begin{tabular}{|c|c|c|c|c|c|c|c|c|}
\hline & \multicolumn{2}{|c|}{ Control (n 25G, 13B) } & \multicolumn{2}{|c|}{$\begin{array}{l}\text { Undernourished } \\
\text { (n 19G, 35B) }\end{array}$} & \multicolumn{2}{|c|}{ Recovered $(n 14 \mathrm{G}, 13 \mathrm{~B})$} & \multicolumn{2}{|c|}{$P \ddagger$} \\
\hline & Mean & $95 \% \mathrm{Cl}$ & Mean & $95 \% \mathrm{Cl}$ & Mean & $95 \% \mathrm{Cl}$ & $\begin{array}{l}\text { Effect of } \\
\text { group }\end{array}$ & $\begin{array}{c}\text { Effect of } \\
\text { sex }\end{array}$ \\
\hline Fasting plasma glucose $(\mathrm{mmol} / \mathrm{l})$ & 4.44 & $4.23,4.64$ & $4 \cdot 26$ & $4.07,4.46$ & $4 \cdot 26$ & $4.04,4.50$ & 0.393 & 0.321 \\
\hline Fasting plasma insulin (pmol//) & $35 \cdot 86$ & $29.77,43.58$ & $27 \cdot 37$ & $22 \cdot 91,33 \cdot 10$ & $35 \cdot 50$ & $28 \cdot 75,44.42$ & 0.097 & 0.505 \\
\hline Insulin sensitivity (HOMA-S, \%) & 132.88 & $109 \cdot 89,161 \cdot 33$ & 177.59 & $147 \cdot 59,216 \cdot 90$ & $138 \cdot 31$ & $110 \cdot 77,172 \cdot 86$ & 0.086 & 0.643 \\
\hline Serum adiponectin $(\mu \mathrm{g} / \mathrm{ml})$ & 22.41 & $18 \cdot 79,27 \cdot 02$ & $22 \cdot 19$ & $18 \cdot 70,26 \cdot 48$ & 21.32 & $17 \cdot 33,26 \cdot 17$ & 0.915 & 0.678 \\
\hline Serum PAl-1 (ng/ml) & $20 \cdot 28$ & $16 \cdot 30,25 \cdot 17$ & 20.69 & $16 \cdot 80,25 \cdot 50$ & $20 \cdot 08$ & $15 \cdot 60,25 \cdot 88$ & 0.982 & 0.053 \\
\hline Serum leptin (ng/ml) & 2.03 & $1.46,2.82$ & $0.92^{*}$ & $0.67,1.25$ & 1.66 & $1 \cdot 15,2.44$ & 0.003 & 0.002 \\
\hline
\end{tabular}

G, girls; B, boys; HOMA-S, homeostasis model assessment of insulin sensitivity; PAI-1, plasminogen activator inhibitor-1.

${ }^{*}$ Mean value was significantly different from those of the control and recovered groups.

†Back-transformed (geometric means).

$\ddagger$ ANCOVA two-way (group and sex) covariates: Tanner stage and age: glucose group $(F(2,89)=0.94)$, sex $(F(1,89)=1.00)$, interaction factor $(F(2,89)=0.67) ; P=0.513\}$; insulin \{group $(F(2,92)=2 \cdot 39)$, sex $(F(1,92)=0.45)$, interaction factor $(F(2,92)=1 \cdot 27) ; P=0.286$; HOMA-S group $(F(2,88)=2 \cdot 52)$, sex $(F(1,88)=0 \cdot 21)$, interaction factor $(F(2,88)=1.66) ; P=0.196\}$; adiponectin group $(F(2,95)=0.09)$, sex $(F(1,95)=0.17)$, interaction factor $(F(2,95)=0.96) ; P=0.386\} ; \mathrm{PAl}-1$ \{group $(F(2,91)=0.02)$, sex $(F(1,91)=3 \cdot 85)$, interaction factor $(F(2,91)=2 \cdot 23) ; P=0 \cdot 113\}$; leptin group $(F(2,97)=6 \cdot 22)$, sex $(F(1,97)=10 \cdot 21)$, interaction factor $(F(2,97)=0 \cdot 03) ; P=0 \cdot 969\}$.

group was significantly greater than that of children in the other two groups. The undernourished group had significantly lower HAZ (minimum $=-3.14$ and maximum $=0.81$ ) and BAZ (minimum $=-3.40$ and maximum $=0.99$ ) values than the other two groups. There were no significant differences in HAZ and BAZ values between the control and recovered groups. The WHR was significantly higher in boys than in girls (0.83 (sE 0.01) and 0.80 (sE 0.01), respectively), but no difference was found among the groups. There was no significant difference in the distribution of children according to their pubertal stages among the groups $\left(\chi^{2}, P=0.773\right)$.

The metabolic characteristics of the study groups are summarised in Table 2. Despite a tendency towards increasing insulin sensitivity being observed in the undernourished group, no changes were observed in glucose metabolism among the groups. Girls exhibited an increased PAI-1 trend in comparison with boys (mean 23.80 (95\% CI 19.60, $28.98) \mathrm{ng} / \mathrm{ml}$ and $17.28 \quad(95 \%$ CI $14.02, \quad 21.56) \mathrm{ng} / \mathrm{ml})$ $(P=0.053)$. There were no differences in adiponectin or PAI-1 concentrations among the groups. However, the undernourished group had significantly lower leptin concentrations than the other two groups. The leptin concentrations of the recovered group were similar to those of the control group. In addition, girls had significantly higher leptin concentrations than boys (Fig. 1). The interactions between groups and sexes were not significant (Table 2). Thus, we obtained similar results for leptin values for boys and girls; that is, both boys and girls of the undernourished group had lower concentrations of this hormone, while both boys and girls of the recovered group had values similar to those of boys and girls of the control group (Fig. 1).

The correlations among anthropometric variables, plasma glucose concentrations, insulin concentrations, HOMA-S and serum adipokine concentrations in girls and boys of each of the three groups are summarised in Tables 3 and 4. A positive correlation between WC and HAZ was found in girls of the control group (but not in those of the other groups) (Table 3). In contrast, a positive correlation between WC and BAZ was found in girls of the undernourished and recovered groups, and this correlation was very strong in the latter group. Insulin concentrations were positively correlated with HAZ and WC and negatively correlated with the WHR in girls of the control group. Plasma glucose concentration were also correlated with WC in girls of the undernourished group; however, only in girls of the control group, glucose concentration were correlated with HAZ. There was no correlation between plasma insulin concentrations and any of the anthropometric variables in girls of the undernourished group; however, very strong correlations among insulin concentrations, BAZ and WC were found in the recovered group. A negative correlation was also observed among insulin sensitivity (HOMA-S), HAZ and central fat (WC) accumulation in addition to a positive correlation with the WHR in girls of the control group. HOMA-S was not correlated

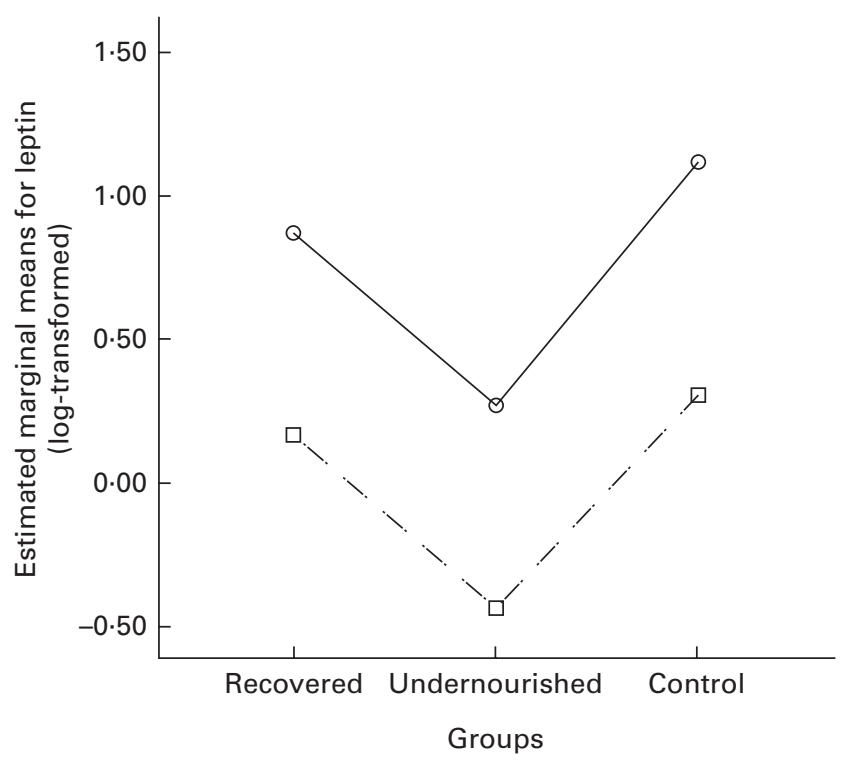

Fig. 1. Serum leptin concentrations of the study groups divided by sex. Boys (-) have significantly lower leptin concentrations than girls (.-). Leptin concentrations in both sexes in the undernourished group were significantly lower than those in other two groups. Details of two-way ANCOVA are given in Table 2. 
Table 3. Correlations between anthropometric variables and adipokine concentrations in girls $\dagger$

\begin{tabular}{|c|c|c|c|c|c|c|c|c|c|}
\hline & HAZ & $\mathrm{BAZ}$ & WC & WHR & Insulin & Glucose & HOMA-S & Adiponectin & PAl-1 \\
\hline \multicolumn{10}{|l|}{ Control (n 25) } \\
\hline BAZ & 0.374 & & & & & & & & \\
\hline WC & $0.485^{\star}$ & 0.362 & & & & & & & \\
\hline WHR & -0.041 & 0.140 & $-0.411^{*}$ & & & & & & \\
\hline Insulin & $0.506^{\star *}$ & 0.048 & $0.633^{\star *}$ & $-0.494^{\star}$ & & & & & \\
\hline Glucose & $0.430^{*}$ & 0.367 & 0.046 & 0.312 & 0.183 & & & & \\
\hline HOMA-S & $-0.521^{*}$ & -0.067 & $-0.630^{\star \star}$ & $0.474^{\star}$ & $-0.999^{\star \star}$ & -0.231 & & & \\
\hline Adiponectin & 0.345 & -0.295 & 0.098 & -0.034 & 0.219 & 0.037 & -0.219 & & \\
\hline PAl-1 & 0.370 & 0.151 & 0.172 & 0.136 & 0.007 & 0.168 & -0.015 & 0.138 & \\
\hline Leptin & $0.452^{*}$ & 0.266 & $0.729^{\star \star}$ & $-0.534^{\star \star}$ & $0.532^{\star \star}$ & -0.110 & $-0.522^{\star \star}$ & 0.269 & 0.189 \\
\hline \multicolumn{10}{|c|}{ Undernourished $(n 17)$} \\
\hline BAZ & $-0.580^{\star \star}$ & & & & & & & & \\
\hline WC & -0.136 & $0.461^{*}$ & & & & & & & \\
\hline WHR & 0.157 & -0.294 & -0.183 & & & & & & \\
\hline Insulin & -0.339 & 0.438 & 0.313 & -0.134 & & & & & \\
\hline Glucose & 0.095 & -0.205 & $-0.616^{\star \star}$ & 0.121 & -0.030 & & & & \\
\hline HOMA-S & 0.322 & -0.411 & -0.249 & 0.134 & $-0.997^{\star \star}$ & -0.048 & & & \\
\hline Adiponectin & 0.199 & -0.015 & -0.205 & -0.270 & 0.252 & 0.125 & -0.261 & & \\
\hline PAI-1 & -0.030 & -0.095 & -0.360 & -0.222 & -0.130 & 0.156 & 0.092 & 0.093 & \\
\hline Leptin & -0.287 & $0.613^{\star \star}$ & $0.490^{*}$ & -0.167 & 0.417 & -0.409 & -0.372 & -0.128 & -0.049 \\
\hline \multicolumn{10}{|c|}{ Recovered ( $n$ 14) } \\
\hline BAZ & 0.068 & & & & & & & & \\
\hline WC & 0.138 & $0.869^{\star \star}$ & & & & & & & \\
\hline WHR & -0.464 & -0.030 & -0.201 & & & & & & \\
\hline Insulin & -0.083 & $0.834^{\star *}$ & $0.802^{\star \star}$ & -0.026 & & & & & \\
\hline Glucose & 0.042 & 0.050 & 0.009 & 0.505 & -0.075 & & & & \\
\hline HOMA-S & 0.059 & $-0.849^{\star \star}$ & $-0.863^{\star \star}$ & -0.032 & $-0.993^{\star \star}$ & -0.046 & & & \\
\hline Adiponectin & -0.337 & 0.358 & 0.263 & -0.039 & $0.537^{\star}$ & -0.256 & -0.502 & & \\
\hline PAI-1 & 0.135 & 0.050 & 0.215 & -0.085 & 0.269 & -0.174 & -0.234 & -0.176 & \\
\hline Leptin & 0.130 & $0.819^{\star \star}$ & $0.829^{\star \star}$ & -0.251 & $0.893^{\star \star}$ & -0.086 & $-0.884^{\star \star}$ & 0.513 & 0.154 \\
\hline
\end{tabular}

HAZ, height-for-age $Z$ score; BAZ, BMI-for-age $Z$ score; WC, waist circumference; WHR, waist:hip ratio; HOMA-S, homeostasis model assessment of insulin sensitivity; PAl-1, plasminogen activator inhibitor-1.

Values were significantly different: ${ }^{*} P<0.05,{ }^{* *} P<0.01$

† Log-transformed values of insulin, glucose, HOMA-S, adiponectin, PAI-1 and leptin.

with any of the anthropometric variables in girls of the undernourished group, whereas it was very strongly correlated with BAZ and WC in girls of the recovered group than in those of the control group. A positive correlation between adiponectin and insulin concentrations was found only in the recovered group. There was no correlation between PAI1 concentrations and any of the variables in girls. However, leptin concentrations were positively correlated with WC in each of the three groups and with BAZ in the undernourished and recovered groups, and the correlation was very strong in the recovered group. Leptin concentrations were correlated with HAZ only in the control group. Nonetheless, a positive correlation between leptin and insulin concentrations and a negative correlation between leptin concentrations and HOMA-S were found in the control and recovered groups, and these correlations were very strong in the recovered group.

A positive correlation between BAZ and WC was found in boys of all the three groups. BAZ was positively correlated not only with WC but also with the WHR in the undernourished group (Table 4). In addition, positive correlations among WC, plasma glucose concentrations and insulin concentrations and a negative correlation between WC and insulin sensitivity were found in boys of the control group. However, there were no correlations among these parameters in the other groups. A negative correlation between adiponectin and insulin concentrations and a positive correlation between adiponectin concentrations and HOMA-S were found in boys of the control group, but there was no correlation with adiponectin concentrations in the other two groups. The only correlation found between PAI-1 concentrations and the studied parameters was a positive correlation with glucose concentrations in the recovered group. Leptin concentrations were negatively correlated with HAZ in the undernourished group and positively correlated with BAZ in the undernourished and control groups. A very strong positive correlation between leptin and insulin concentrations was found in the recovered group, whereas a weak positive correlation was found in the undernourished group; there was no correlation between these factors in the control group. Moreover, a negative correlation between leptin concentrations and HOMA-S was found in the undernourished and recovered groups, and this correlation was stronger in the latter group.

\section{Discussion}

Low- and middle-income countries that are challenged by the dual burden of persistent undernutrition and emerging obesity should very carefully monitor early growth rates in children. It is known that early linear growth strongly predicts adult height, lean body mass, educational attainment, employment and earnings ${ }^{(36)}$. The literature also indicates that a rapid 
Table 4. Correlations between anthropometric variables and adipokine concentrations in boys $†$

\begin{tabular}{|c|c|c|c|c|c|c|c|c|c|}
\hline & HAZ & $\mathrm{BAZ}$ & WC & WHR & Insulin & Glucose & HOMA-S & Adiponectin & PAI-1 \\
\hline \multicolumn{10}{|l|}{ Control (n 13) } \\
\hline BAZ & 0.117 & & & & & & & & \\
\hline WC & 0.403 & $0.651^{\star}$ & & & & & & & \\
\hline WHR & -0.160 & 0.453 & 0.101 & & & & & & \\
\hline Insulin & 0.237 & 0.424 & $0.630^{*}$ & -0.164 & & & & & \\
\hline Glucose & 0.411 & 0.190 & $0.778^{\star \star}$ & -0.092 & 0.557 & & & & \\
\hline HOMA-S & -0.255 & -0.423 & $-0.656^{\star}$ & 0.162 & $-0.999^{\star \star}$ & $-0.599^{\star}$ & & & \\
\hline Adiponectin & 0.080 & -0.370 & -0.301 & -0.004 & $-0.624^{\star}$ & -0.080 & $0.607^{\star}$ & & \\
\hline PAl-1 & 0.109 & 0.088 & 0.217 & 0.509 & 0.234 & 0.134 & -0.233 & -0.176 & \\
\hline Leptin & 0.247 & $0.690^{*}$ & $0.673^{\star}$ & 0.227 & 0.543 & 0.393 & -0.550 & -0.245 & 0.114 \\
\hline \multicolumn{10}{|c|}{ Undernourished (n 33) } \\
\hline $\mathrm{BAZ}$ & $-0.611^{\star \star}$ & & & & & & & & \\
\hline WC & -0.176 & $0.429^{*}$ & & & & & & & \\
\hline WHR & -0.214 & $0.473^{\star \star}$ & 0.093 & & & & & & \\
\hline Insulin & -0.232 & 0.327 & 0.281 & 0.047 & & & & & \\
\hline Glucose & 0.099 & -0.040 & -0.115 & 0.053 & -0.202 & & & & \\
\hline HOMA-S & 0.224 & -0.282 & -0.238 & 0.040 & $-0.994^{\star \star}$ & 0.093 & & & \\
\hline Adiponectin & -0.133 & 0.120 & 0.004 & 0.076 & 0.001 & -0.047 & -0.018 & & \\
\hline PAl-1 & -0.079 & 0.112 & -0.147 & 0.053 & 0.308 & -0.076 & -0.324 & -0.088 & \\
\hline Leptin & $-0.397^{\star}$ & $0.455^{\star \star}$ & 0.308 & 0.057 & $0.374^{*}$ & -0.162 & $-0.371^{*}$ & 0.101 & 0.193 \\
\hline \multicolumn{10}{|c|}{ Recovered ( $n$ 11) } \\
\hline BAZ & -0.108 & & & & & & & & \\
\hline WC & -0.105 & $0.618^{*}$ & & & & & & & \\
\hline WHR & 0.071 & -0.156 & -0.363 & & & & & & \\
\hline Insulin & -0.364 & 0.126 & 0.196 & -0.223 & & & & & \\
\hline Glucose & -0.251 & -0.486 & -0.064 & -0.120 & 0.361 & & & & \\
\hline HOMA-S & 0.373 & -0.085 & -0.185 & 0.228 & $-0.997^{\star \star}$ & -0.431 & & & \\
\hline Adiponectin & -0.392 & 0.106 & 0.202 & -0.332 & -0.051 & 0.129 & 0.037 & & \\
\hline PAl-1 & -0.091 & -0.039 & 0.360 & -0.261 & 0.326 & $0.679^{\star}$ & -0.372 & 0.282 & \\
\hline Leptin & 0.015 & 0.216 & 0.442 & -0.388 & $0.820^{\star *}$ & 0.244 & $-0.814^{\star *}$ & -0.251 & 0.393 \\
\hline
\end{tabular}

HAZ, height-for-age Z score; BAZ, BMI-for-age Z score; WC, waist circumference; WHR, waist:hip ratio; HOMA-S, homeostasis model assessment of insulin sensitivity; PAI-1, plasminogen activator inhibitor-1.

Values were significantly different: ${ }^{*} P<0.05,{ }^{* *} P<0.01$.

† Log-transformed values of insulin, glucose, HOMA-S, adiponectin, PAI-1 and leptin.

weight gain among children suffering from undernutrition in early life is associated with the development of obesity and co-morbidities in the future ${ }^{(37-39)}$. In this condition, it is very important to monitor adipose tissue metabolism during nutritional recovery.

The results of the present study, which are in agreement with the literature, showed that undernourished children had lower leptin concentrations ${ }^{(4,5)}$. Studies in undernourished children who underwent short-term nutritional recovery focusing primarily on increasing weight found leptin values of these children to be higher than those of the control children. Büyükgebiz et al. ${ }^{(40)}$ studied mildly undernourished children undergoing out-patient treatment for 6 months and found an increase in their body weight from 84 to $97 \%$, but no recovery in their stature. They found large increases in the concentrations of leptin $(3.3-6.7 \mathrm{ng} / \mathrm{ml} ; P<0.05)$ in this condition. In another study, children with kwashiorkor and marasmus were treated with a commercial formula and found to exhibit a 1.5-2-fold increase in their leptin concentrations in comparison with the control values ${ }^{(41)}$. Babies were given a formula enriched with lactose and maize syrup for 4 weeks and children aged $>12$ months were supplemented with cereal and/or commercial vegetable pap foods. A 2-fold increase in weight-for age $Z$ scores and weight-for-height $Z$ scores was found in this study, but there were no changes in HAZ. These results differed from those of the present study, because in the present study the recovered and control groups were found to have similar leptin concentrations, which were higher than those of the undernourished group. This difference in comparison with previous studies is most likely caused by the treatment profiles of the CREN, which focuses not only on weight gain but also on linear growth. Previous studies carried out by our research group have found normal body compositions in children who recovered at the CREN, which is in line with the findings of the present study ${ }^{(29)}$. The results of the present study indicate that leptin concentrations reflect the amount of weight gained during recovery. Thus, an adequate treatment that includes the recovery of stature with normal leptin concentrations may prevent undesirable consequences and a future risk of the metabolic syndrome in these children.

The normal adiponectin and PAI-1 concentrations found in children in the recovered group in the present study were consistent with these findings. In the present study, no differences were observed among these groups with regard to adiponectin and PAI-1 concentrations, with the exception of a marginal difference in the concentrations of PAI- 1 in girls, whose values were higher than those of boys. The low adiposity of the recovered children treated at the CREN has been described previously ${ }^{(29)}$, and this finding may explain the present results.

The stronger correlations of serum leptin concentrations with BAZ, WC, insulin concentrations and HOMA-S (with the last one being notably negative) among recovered girls 
calls attention to the fact that this group might require careful weight gain monitoring for the rest of their lives. It is possible that these strong correlations indicate epigenetic changes in the recovered girls. Currently, there is evidence that epigenetic changes in humans may occur in the intra-uterine environment and also during postnatal life; thus, the quality of the environment in which a child lives early in life, especially during the first $1000 \mathrm{~d}$, is crucial to his or her future epigenetic regulation and may affect his or her risk of developing non-communicable diseases in adulthood ${ }^{(42,43)}$.

It is well known that adiponectin has protective actions against the development of type 2 diabetes mellitus as it increases insulin sensitivity ${ }^{(44)}$. Children (aged 6-11 years) born with low birth weights ( $2500 \mathrm{~g}$ ) were found to have significantly lower concentrations of adiponectin and significantly higher HOMA-IR (which assesses resistance to insulin) in comparison with the controls ${ }^{(45)}$. In the present study, no differences were found in adiponectin concentrations among the groups. A negative correlation between adiponectin and insulin concentrations and a positive correlation between adiponectin concentrations and HOMA-S were found in boys of the control group, as expected, but not in girls. However, adiponectin concentrations were positively correlated with insulin concentrations in girls of the recovered group, and HOMA-S had a marginally negative correlation $(P=0.08)$. Further studies are required to investigate this relationship.

Studies carried out in children adopted from developing countries and then taken to high-income countries have demonstrated that linear growth after adoption can be associated with early pubertal development, but only if undernutrition occurs during the fetal or fetal-postnatal period ${ }^{(46)}$. In the present study, no early or late pubertal development was found in the study groups. It is possible that changes in the country, living conditions and diet acted as clear determining factors for the early pubertal development found in adopted children, but none of these children were separated from their families of origin or underwent radical changes in their environmental conditions.

The two limitations of the present study that must be considered are the rather small number of children studied and the cross-sectional design. In addition, there was a difference in age between children in the undernourished group and those in the other two groups. One possible explanation is that the nutritional condition of Brazilian children has improved during the last decade and the undernourished children were older children who were born in poorer conditions that no longer exist ${ }^{(47)}$. In any case, all analyses comparing adipokine concentrations among the groups were adjusted for age and pubertal stage to correct for this difference.

In conclusion, the results of present study show that children who are treated according to CREN's model of recovery, which allows for a recovery in not only in weight but also in height, have unelevated leptin concentrations. In these conditions, we can expect that they are likely to be better protected against future non-communicable diseases. However, there is no assurance that the leptin values will continue to be normal later in life, and longitudinal studies are required to confirm this finding. Nevertheless, the maintenance of a healthy lifestyle, especially in recovered girls, should be carefully monitored because of the stronger correlations among leptin concentrations, BAZ, WC and insulin concentrations.

\section{Acknowledgements}

The present study was supported by the FAPESP (Fundação de Amparo à Pesquisa do Estado de São Paulo, Brazil), grant number 2010/51237-2. V. J. B. M. was supported by the CAPES (Coordenação de Aperfeiçoamento de Pessoal de Nível Superior) and A. L. S. was supported by a CNPQ (Conselho Nacional de Desenvolvimento Científico e Tecnológico) fellowship, number 302740/2010-4. FAPESP, CAPES and CNPq had no role in the design and analysis of the study or in the writing of this article.

The authors' contributions are as follows: V. J. B. M., M. d. C. P. F. and A. L. S. designed the study; V. J. B. M. and A. P. O. N. collected the data; V. J. B. M. and A. L. S. carried out the statistical analyses, interpreted the data and wrote the article; A. P. G. C. contributed to the statistical analyses and revision of the article. All authors critically revised the article and approved the final version.

None of the authors has any conflicts of interest to declare.

\section{References}

1. Kershaw EE \& Flier JS (2004) Adipose tissue as an endocrine organ. J Clin Endocrinol Metab 89, 2548-2556.

2. Trayhurn P \& Wood IS (2004) Adipokines: inflammation and the pleiotropic role of white adipose tissue. BrJ Nutr $\mathbf{9 2}$, $347-355$.

3. Vickers MH \& Sloboda DM (2012) Leptin as mediator of the effects of developmental programming. Best Pract Res Clin Endocrinol Metab 26, 677-687.

4. Soliman AT, ElZalabany MM, Salama M, et al. (2000) Serum leptin concentrations during severe protein-energy malnutrition: correlation with growth parameters and endocrine function. Metabolism 49, 819-825.

5. Büyükgebiz B, Oztürk Y, Yilmaz S, et al. (2003) Serum leptin concentrations in children with mild-to-moderate proteinenergy malnutrition. Pediatr Int 45, 550-554.

6. Nienaber C, Pieters M, Kruger SH, et al. (2008) Overfatness, stunting and physical inactivity are determinants of plasminogen activator inhibitor-1 activity, fibrinogen and thrombin-antithrombin complex in African adolescents. Blood Coagul Fibrinolysis 19, 361-368.

7. Lakshmy R, Fall CH, Sachdev HS, et al. (2011) Childhood body mass index and adult pro-inflammatory and prothrombotic risk factors: data from the New Delhi birth cohort. Int J Epidemiol 40, 102-111.

8. Black RE, Victora CG, Walker SP, et al. (2013) Maternal and child undernutrition and overweight in low-income and middle-income countries. Lancet 382, 427-451.

9. Martins VJ, Toledo Florêncio TM, Grillo LP, et al. (2011) Long-lasting effects of undernutrition. Int J Environ Res Public Health 8, 1817-1846.

10. The World Bank (2006) Repositioning Nutrition as Central to Development. A Strategy for Large-Scale Action. Washington, DC: The World Bank. http://siteresources.worldbank.org/ NUTRITION/Resources/281846-1131636806329/NutritionStrategy.pdf (accessed October 2013). 
11. Barquera S, Peterson KE, Must A, et al. (2007) Coexistence of maternal central adiposity and child stunting in Mexico. Int J Obes (Lond) 31, 601-607.

12. Oddo VM, Rah JH, Semba RD, et al. (2012) Predictors of maternal and child double burden of malnutrition in rural Indonesia and Bangladesh. Am J Clin Nutr 95, 951-958.

13. Le Nguyen BK, Le Thi H, Nguyen Do VA, et al. (2013) Double burden of undernutrition and overnutrition in Vietnam in 2011: results of the SEANUTS study in 0.5-11-yearold children. Br J Nutr 110, Suppl. 3, S45-S56.

14. Martins PA, Hoffman DJ, Fernandes MT, et al. (2004) Stunted children gain less lean body mass and more fat mass than their non-stunted counterparts: a prospective study. $\mathrm{Br} J$ Nutr 92, 819-825.

15. Clemente AP, Santos CD, Martins VJ, et al. (2011) Mild stunting is associated with higher body fat: study of a low-income population. J Pediatr 87, 138-144.

16. Hoffman DJ, Martins PA, Roberts SB, et al. (2007) Body fat distribution in stunted compared with normal-height children from the shantytowns of São Paulo, Brazil. Nutrition 23, 640-646.

17. Hoffman DJ, Sawaya AL, Verreschi I, et al. (2000) Why are nutritionally stunted children at increased risk of obesity? Studies of metabolic rate and fat oxidation in shantytown children from São Paulo, Brazil. Am J Clin Nutr 72, 702-707.

18. Hoffman DJ, Sawaya AL, Coward WA, et al. (2000) Energy expenditure of stunted and nonstunted boys and girls living in the shantytowns of São Paulo, Brazil. Am J Clin Nutr 72, 1025-1031.

19. Grillo LP, Siqueira AF, Silva AC, et al. (2005) Lower resting metabolic rate and higher velocity of weight gain in a prospective study of stunted vs nonstunted girls living in the shantytowns of São Paulo, Brazil. Eur J Clin Nutr 59, 835-842.

20. Florêncio TT, Ferreira HS, Cavalcante JC, et al. (2004) Short stature, obesity and arterial hypertension in a very low income population in North-eastern Brazil. Nutr Metab Cardiovasc Dis 14, 26-33.

21. Sesso R, Barreto GP, Neves J, et al. (2004) Malnutrition is associated with increased blood pressure in childhood. Nephron Clin Pract 97, c61-c66.

22. González-Barranco J, Ríos-Torres JM, Castillo-Martínez L, et al. (2003) Effect of malnutrition during the first year of life on adult plasma insulin and glucose tolerance. Metabolism 52, 1005-1011.

23. Eriksson JG, Forsén T, Tuomilehto J, et al. (1999) Catch-up growth in childhood and death from coronary heart disease: longitudinal study. BMJ 318, 427-431.

24. Ong KK, Ahmed ML, Emmett PM, et al. (2000) Association between postnatal catch-up growth and obesity in childhood: prospective cohort study. BMJ 320, 967-971.

25. Stettler N, Zemel BS, Kumanyika S, et al. (2002) Infant weight gain and childhood overweight status in a multicenter, cohort study. Pediatrics 109, 194-199.

26. Alves-Vieira Mde F, Ferraro AA, Nascimento Souza MH, et al. (2010) Height and weight gains in a nutrition rehabilitation day-care service. Public Health Nutr 13, 1505-1510.

27. Fernandes MB, López RV, de Albuquerque MP, et al. (2012) A 15-year study on the treatment of undernourished children at a nutrition rehabilitation centre (CREN), Brazil. Public Health Nutr 15, 1108-1116.

28. Martins VJ, Martins PA, Neves Jd, et al. (2008) Children recovered from malnutrition exhibit normal insulin production and sensitivity. Br J Nutr 99, 297-302.

29. das Neves J, Martins PA, Sesso R, et al. (2006) Malnourished children treated in day-hospital or outpatient clinics exhibit linear catch-up and normal body composition. I Nutr 136 , 648-655.

30. Singhal A \& Lucas A (2004) Early origins of cardiovascular disease: is there a unifying hypothesis? Lancet 363, 1642-1645.

31. Frisancho AR (2008) Evaluation of postnatal growth and nutritional status of children and adults using the NHANES III anthropometric reference. In Anthropometric Standards: An Interactive Nutritional Reference of Body Size and Body Composition for Children and Adults, 2nd ed., pp. 303-331 [RA Frisancho, editor]. Ann Arbor, MI: University of Michigan Press.

32. Tanner JM (1962) The development of the reproductive system. In Growth at Adolescence, 2nd ed., pp. 28-39 [JM Tanner, editor]. Oxford: Blackwell Scientific Publications.

33. Word Health Organization (1995) Physical Status: The Use and Interpretation of Anthropometry. Infants and Children. Technical Report Series no. 854. Geneva: WHO.

34. University of Oxford (2004) Homa Calculator. http:// www.dtu.ox.ac.uk/homacalculator/download.php (accessed August 2013)

35. Arrode-Brusés G \& Brusés JL (2012) Maternal immune activation by poly (I:C) induces expression of cytokines IL-1 $\beta$ and IL-13, chemokine MCP-1 and colony stimulating factor VEGF in fetal mouse brain. J Neuroinflammation 9, 83 .

36. Adair LS, Fall CH, Osmond C, et al. (2013) Associations of linear growth and relative weight gain during early life with adult health and human capital in countries of low and middle income: findings from five birth cohort studies. Lancet 382, 525-534.

37. Stettler N \& Iotova V (2010) Early growth patterns and long-term obesity risk. Curr Opin Clin Nutr Metab Care 13, 294-299.

38. Demerath EW, Reed D, Choh AC, et al. (2009) Rapid postnatal weight gain and visceral adiposity in adulthood: the Fels Longitudinal Study. Obesity 17, 2060-2066.

39. Dulloo AG (2008) Thrifty energy metabolism in catch-up growth trajectories to insulin and leptin resistance. Best Pract Res Clin Endocrinol Metab 22, 155-171.

40. Büyükgebiz B, Oztürk Y, Yilmaz S, et al. (2004) Serum leptin concentrations in children with mild protein-energy malnutrition and catch-up growth. Pediatr Int 46, 534-538.

41. Stein K, Vasquez-Garibay E, Kratzsch J, et al. (2006) Influence of nutritional recovery on the leptin axis in severely malnourished children. J Clin Endocrinol Metab 91, 1021-1026.

42. Lillycrop KA \& Burdge GC (2012) Epigenetic mechanisms linking early nutrition to long term health. Best Pract Res Clin Endocrinol Metab 26, 667-676.

43. Prentice AM, Ward KA, Goldberg GR, et al. (2013) Critical windows for nutritional interventions against stunting. Am J Clin Nutr 97, 911-918.

44. Brochu-Gaudreau K, Rehfeldt C, Blouin R, et al. (2010) Adiponectin action from head to toe. Endocrine 37, 11-32.

45. Strufaldi MW, Puccini RF, Silvério OM, et al. (2013) Association of adipokines with cardiovascular risk factors in low birth weight children: a case-control study. Eur J Pediatr 172, 71-76

46. Proos L \& Gustafsson J (2012) Is early puberty triggered by catch-up growth following undernutrition? Int J Environ Res Public Health 9, 1791-1809.

47. Instituto Brasileiro de Geografia e Estatística (2010) Pesquisa de Orçamentos familiares 2008-2009 - Antropometria e Estado Nutricional de Crianças e Adolescentes (Housebold Budget Survey 2008-2009 - Anthropometry and Nutritional Status of Children and Adolescents). Rio de Janeiro: Instituto Brasileiro de Geografia e Estatística. http://www.ibge.gov.br/home/estatistica/populacao/condicaodevida/pof/ 2008_2009_encaa/default.shtm (in Portuguese). 